\title{
Palmoplantar Involvement in Leprosy: A Clinicopathological Study
}

\author{
Garima Dabas, ${ }^{1}$ Tarun Narang, ${ }^{1 *}$ Sunil Dogra, ${ }^{1}$ Divya Aggarwal, ${ }^{2}$ and Bishan Das Radotra ${ }^{2}$ \\ ${ }^{1}$ Department of Dermatology, Venereology and Leprology, Postgraduate Institute of Medical Education and Research (PGIMER), Chandigarh, \\ India; ${ }^{2}$ Department of Histopathology, Postgraduate Institute of Medical Education and Research (PGIMER), Chandigarh, India
}

\begin{abstract}
Palmoplantar involvement has been infrequently reported in leprosy and is an easily misdiagnosed entity. The institutional database of leprosy clinic from 2015 to 2018 was accessed. Details pertaining to demography, clinical presentation, comorbidities (if any), treatment received, and outcome were analyzed in leprosy patients with palmoplantar involvement. Among the 520 patients studied, the involvement of palms and/or soles was reported in 49 (9.4\%) patients. Isolated palm involvement was the most frequent $(26 / 49,53.1 \%)$, followed by both palm and sole involvement (12/49, $24.5 \%)$ and sole involvement alone $(11 / 49,22.4 \%)$. A higher incidence of lepra reactions and disabilities was noted in patients with palmoplantar involvement than in those without $(P<0.0001)$. Palmoplantar involvement in leprosy, although uncommon, is associated with a higher risk of reactions and disabilities. A knowledge of this aspect of leprosy can help in maintaining a high index of suspicion and reduce misdiagnosis.
\end{abstract}

Leprosy is a chronic infectious disease caused by Mycobacterium leprae, which primarily affects areas of the body which have a relatively lower temperature. ${ }^{1}$ Palms, soles, scalp, genitalia, groins, and axillae are usually considered relatively spared zones to leprosy (immune zones), ${ }^{2}$ owing to their high local temperature. ${ }^{3,4}$ However, clinical, histological, and bacteriological evidence of involvement of these areas has been infrequently documented in the literature. ${ }^{5-7}$ The presence of high nerve bed temperature in palms and soles owing to thicker epidermis and greater amount of fibro-fatty tissue reduces risk of the localization of $M$. leprae in these areas. $^{4,8-10}$ The objective was to study the prevalence of palmoplantar lesions in leprosy and to explore the clinical, histopathological, and demographic data pertaining to the palmo-plantar involvement in leprosy.

All data for this retrospective study were collected from the case record forms of leprosy patients registered at the leprosy disease clinic of the Department of Dermatology, Venereology and Leprology at Postgraduate Institute of Medical Education and Research, Chandigarh, India, between April 2015 and June 2018. Data was analyzed from September 2 through December 30, 2019. The detailed clinical description of lesions, nerve involvement (if any), disability (if any), reactions (if any), and response to treatment of leprosy patients were recorded in a predesigned proforma. The clinical and demographic features of the leprosy patients with palmoplantar involvement (subjects, $n=49$ ) were compared with those without the involvement of the palms and soles (controls, $n=471$ ).

Descriptive statistics were used for clinical features and histopathology. Statistical analyses were performed using the chi-square test/Fisher's exact test for categorical data and the Student's $t$-test/Mann-Whitney test for continuous data as appropriate using Statistical Package for the Social Sciences (SPSS) v. 23 (IBM, Armonk, NY). Multivariate logistic regression was performed for statistically significant variables, for patients with and without palmoplantar involvement. All tests were evaluated for $95 \%$ confidence limits; a $P$-value of $\leq 0.05$ was considered statistically significant.

\footnotetext{
*Address correspondence to Tarun Narang, Department of Dermatology, Venereology and Leprology, Postgraduate Institute of Medical Education and Research (PGIMER), Sector 12, Chandigarh 160012, India. E-mail: narangtarun@yahoo.co.in
}

A total of 520 leprosy patients were included in the study, and palm and/or sole involvement was observed in 49 (9.4\%) patients only. Most leprosy patients with palm and/or sole lesions reported the onset of leprosy lesions on the dorsum of the hands, feet, or on skin away from the palms and soles; only four $(8.1 \%)$ had a primary lesion on the palmoplantar area. Isolated palmar involvement was most frequent (26/49, $53.1 \%)$, followed by the involvement of both the palms and soles $(12 / 49,24.5 \%)$ and only the soles $(11 / 49,22.4 \%)$. The mean duration of disease in patients with palmoplantar involvement was $12.9 \pm 12.1$ months, ranging from 2 months to 5 years. The majority of patients $(28 / 49,57.1 \%)$ had the disease for less than 1 year. There was no correlation between the duration of disease and palmoplantar involvement $(12.9 \pm 12.1$ versus $11.9 \pm 13.4, P=0.58)$. There was no statistically significant difference in the frequency of palmoplantar involvement among different age-groups $(P=$ 0.43 ) and gender distribution (males 34/352, 9.6\% and females $15 / 168,8.9 \%, P=0.52)$. The most frequently involved sites on the palms were the hypothenar eminence $(26 / 38$, $68.4 \%)$, thenar eminence $(22 / 38,57.9 \%)$, edges of the palm $(12 / 38,31.5 \%)$, and ventral aspect of the proximal and middle phalanx $(10 / 38,26.3 \%)$. The center of the palm $(5 / 38$, $13.2 \%)$ and palmar flexion creases $(6 / 38,15.8 \%)$ were less frequently affected, suggestive of palmar deck chair sign. On the soles, the instep was the most frequently affected site $(15 / 23,65.2 \%)$, followed by balls of the feet $(13 / 23,56.5 \%)$ and ventral aspect of the toes $(9 / 23,39.1 \%)$. The involvement of heels $(2 / 23,8.7 \%)$ and edges of the sole $(3 / 23,13.0 \%)$ was infrequent.

Palmoplantar lesions were mostly observed in lepromatous leprosy (LL) (19/49, 38.7\%) patients, followed by borderline lepromatous leprosy (BL) (15/49, 30.6\%) (Table 1). The clinical presentation of palmoplantar lesions varied across the spectrum of the disease (Figure 1). A female patient with histoid leprosy downgraded from BL and presented with erythematous patches on the hand and histoid lesions in the forearm (Figure 1, O, P).

Lepra reactions were more commonly observed in patients with palmoplantar involvement than in those without $(24 / 49$, $48.9 \%$ versus $91 / 471,19.3 \% ; P<0.0001)$. The lesions became more erythematous during reactional episodes, and five patients suffered from persistent paresthesia even after the 
TABLE 1

Clinical manifestation of leprosy patients with palmoplantar involvement in our series

\begin{tabular}{|c|c|c|c|c|c|c|c|c|c|}
\hline \multirow[b]{2}{*}{ S. no } & \multirow[b]{2}{*}{ Type of leprosy } & \multicolumn{3}{|c|}{ Sites involved } & \multirow[b]{2}{*}{ Clinical presentation } & \multicolumn{2}{|c|}{ Reactions } & \multicolumn{2}{|c|}{ Disability } \\
\hline & & Palms & Soles & Both palms and soles & & Type 1 & Type 2 & Grade 1 & Grade 2 \\
\hline 1 & $\pi T$ & 0 & 1 & 0 & Isolated large erythematous patch (1) & 1 & - & - & - \\
\hline 2 & BT & 5 & 3 & 0 & $\begin{array}{l}\text { Isolated large erythematous (1) or } \\
\text { hyperpigmented (2) patch and extension } \\
\text { of erythematous (2) or hyperpigmented } \\
\text { patch from the surrounding area (3) }\end{array}$ & 3 & - & 4 & 2 \\
\hline 3 & BB & 1 & 0 & 0 & Erythematous plaques (1) & - & - & - & - \\
\hline 4 & $\begin{array}{l}\text { Borderline } \\
\text { lepromatous }\end{array}$ & 8 & 3 & 4 & $\begin{array}{l}\text { Small (3) or large (6) erythematous plaques, } \\
\text { diffuse erythema (2), and small } \\
\text { hyperpigmented patches (4) }\end{array}$ & 4 & 5 & 5 & 4 \\
\hline 5 & $\begin{array}{l}\text { Lepromatous } \\
\text { leprosy }\end{array}$ & 11 & 3 & 5 & $\begin{array}{l}\text { Small hyperpigmented patches sparing } \\
\text { the central palm and palmar creases (9), } \\
\text { small erythematous plaques (3), and } \\
\text { erythematous (5) or hyperpigmented } \\
\text { nodules (2) }\end{array}$ & 2 & 8 & 3 & 9 \\
\hline 6 & Histoid & 1 & 1 & 3 & $\begin{array}{l}\text { Erythematous (2) or hyperpigmented (1) } \\
\text { nodules and erythematous plaques ( } 2 \text { ) }\end{array}$ & - & 1 & - & 1 \\
\hline
\end{tabular}

treatment of reactional states. Disabilities were observed in more than half the patients with palmoplantar lesions $(28 / 49$, $57.1 \%$ versus $101 / 471,21.4 \%)$. This difference was statistically significant $(P<0.0001)$. Grade 1 and 2 disabilities were noted in 12 and 16 patients, respectively.

Histopathological changes in the palms and soles corresponded to those observed in cutaneous lesions elsewhere (Figure 2). Epithelioid cell granulomas with lymphocytes and rarely Langhans-type giant cells were seen along with the neurovascular bundles in tuberculoid leprosy, whereas flattened epidermis, grenz zone, and foamy macrophages with few lymphocytes and abundant acid-fast bacilli were noted in lepromatous leprosy. Increased pigmentation was observed in the basal layer in patients with hyperpigmented patches. Posttreatment, hyperpigmented patches persisted in 18 patients, whereas others showed a decrease in pigmentation (Figure 2, I and J).
Hypopigmented anesthetic patches, thickened peripheral nerves, and the presence of acid-fast bacilli (as seen on slitskin smear examination or skin biopsy) are the cardinal signs of leprosy. Primary hyperpigmentation is rare in leprosy; however, secondary pigmentation can occur due to drugs like clofazimine and/or lepra reactions. Most palmoplantar lesions in our report presented with primary hyperpigmentation which differentiates them from lesions on the rest of the body. The exact mechanism of primary hyperpigmentation in leprosy is unclear, and upregulation of melanogenic stimulating factors such as fibroblast growth factor, hepatocyte growth factor, and stem cell factors owing to neurohormonal or biochemical stimulations has been implicated. ${ }^{11,12}$

The clinical presentation of the lesions on the palms and soles corresponded with the type of leprosy. The lesions in LL are numerically more in number, and this increases the chances of occurrence of lesions on the palms and soles also.

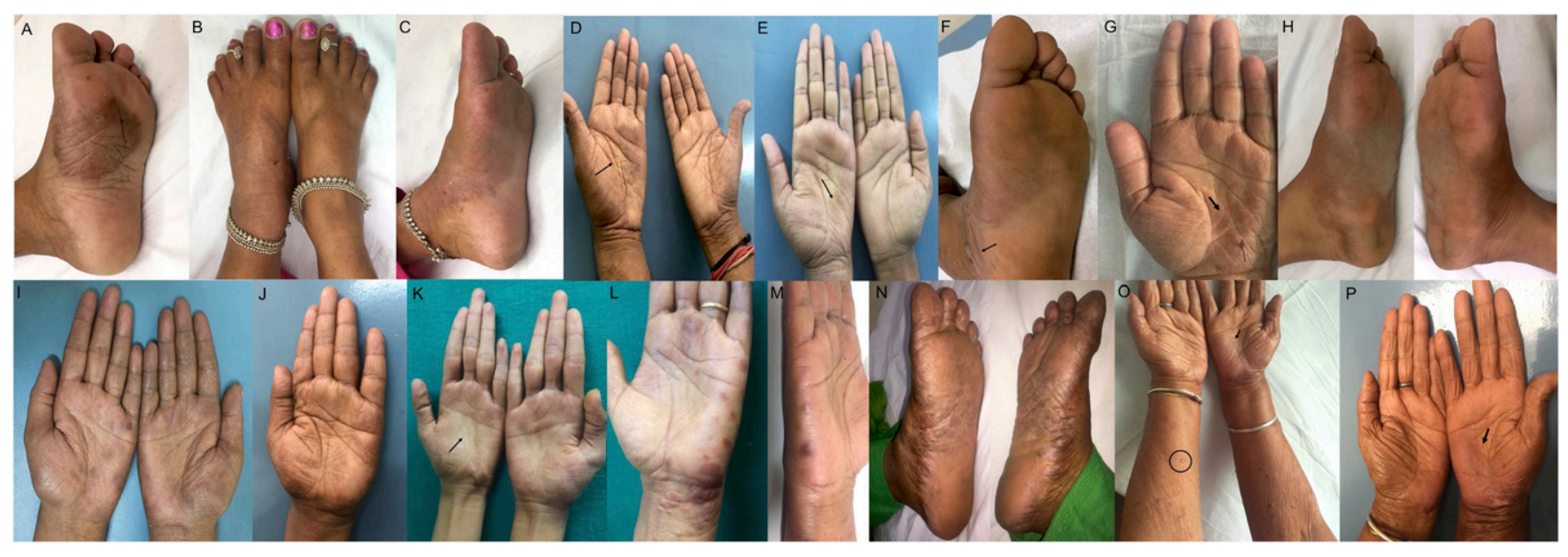

FIGURE 1. (A) Isolated erythematous patch on the sole in TT leprosy. (B and C) Large erythematous patch on the sole extending from the dorsum of the left foot, (D) hyperpigmented patch on the palm, and (E) erythematous patch on the hypothenar eminence with grade 2 disability (marked with an arrow) in BT leprosy. (F) Large erythematous plaque on the foot along with erythema nodosum leprosum lesions on the ankle (black arrow), (G) large ill-defined hyperpigmented patch on the hypothenar eminence, and $(\mathbf{H})$ large erythematous patches present on both feet extending to the dorsum of the feet in borderline lepromatous (BL) leprosy. (I-K) Multiple small erythematous to hyperpigmented patches with (I and K) sparing of central palm and (K) grade 2 disability in LL. (L-N) Multiple erythematous plaques and nodules on the edges of the palm in de novo histoid patients. (O) Histoid lesions on the forearm and $(\mathbf{P})$ erythematous plaque on the palm of an histoid patient downgraded from BL leprosy. This figure appears in color at www.ajtmh.org. 


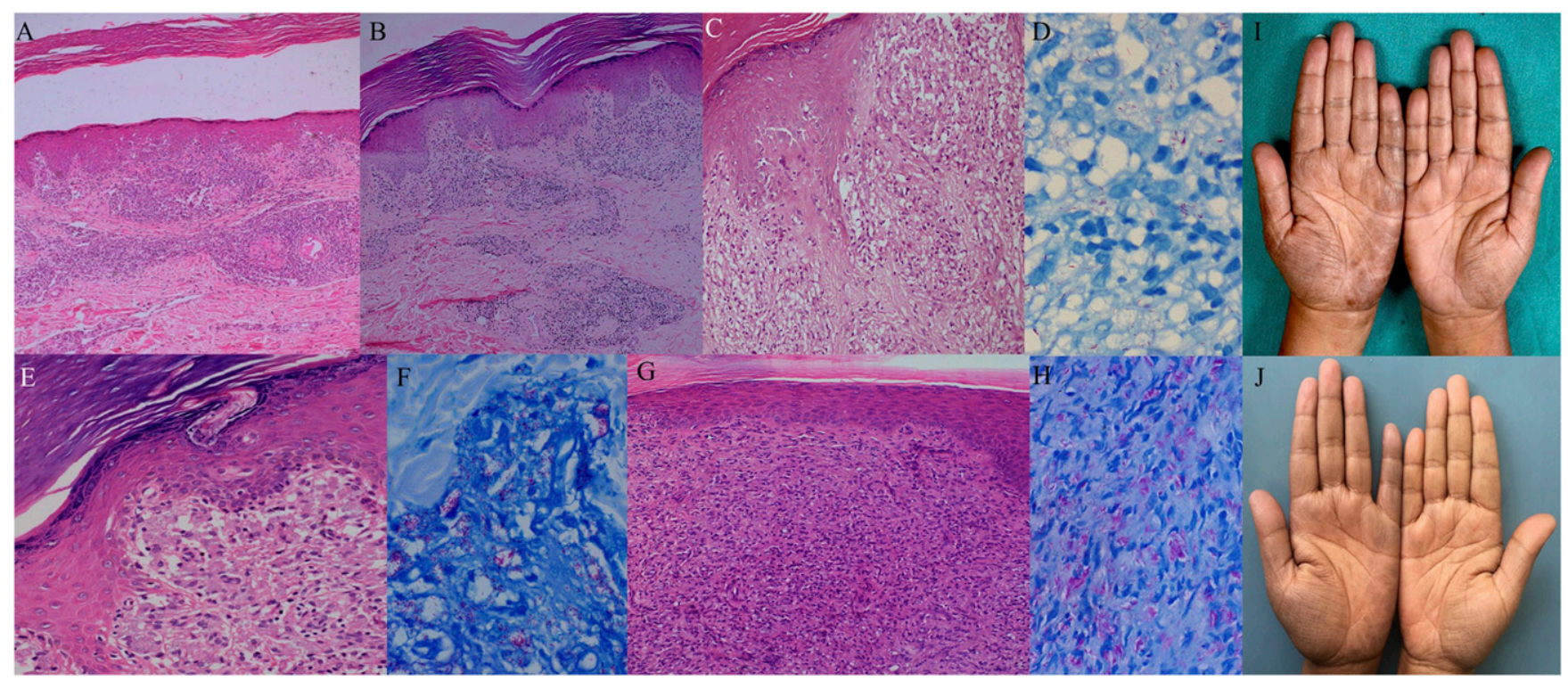

FIGURE 2. Histological spectrum of leprosy lesions over the palms and soles. (A) Large and compact epithelioid cell granulomas along the neurovascular bundles eroding into the basal layer of the epidermis in TT leprosy (hematoxylin and eosin, $\times 40$ ). (B) Curvilinear epithelioid cell granulomas along the neurovascular bundle in BT leprosy (hematoxylin and eosin, $\times 40$ ). (C and D) Granulomas with foamy macrophages and epithelioid cells (hematoxylin and eosin, $\times 100$ ) and (D) positive acid-fast bacilli positive in a borderline lepromatous patient (Ziehl-Neelsen stain, $\times 1000$ ). (E) Thinned-out epidermis with ill-defined granulomas composed of foamy histiocytes (hematoxylin and eosin, $\times 200)$. (F) Biopsy teaming with acid-fast bacilli in an lepromatous leprosy (LL) patient (Ziehl-Neelsen stain, $\times 1000$ ). (G and $\mathbf{H})$ Spindle cell macrophages oriented in a storiform pattern (hematoxylin and eosin, $\times 100$ ) with $(\mathbf{H})$ acid-fast bacilli showing histoid habitus (Ziehl-Neelsen stain, $\times 1000)$. (I and J) Pre- and posttreatment images showing improvement in pigmentation $(\mathbf{J})$ in an LL patient after completion of treatment. This figure appears in color at www.ajtmh.org.

Palmoplantar involvement was observed to be significantly more in patients with reactional states. This can be attributed to the fact that clinically unapparent lesions become obvious during reactions. Also, most patients in our series had BL or LL (39/49, 79.6\%), which explains the higher incidence of type 2 reactions. There was also a greater incidence of disability in patients in our series, owing to the location of the lesions and the nerve involvement. In a study conducted by Arora et al., ${ }^{13}$ 500 leprosy patients were screened, and only 18 cases (3.6\%) showed palmoplantar involvement. In $50 \%$ of their patients, palmoplantar involvement was associated with type 1 reaction. ${ }^{13}$

Post-elimination palmoplantar lesions have been infrequently reported in leprosy as they are easily misdiagnosed and can be confused with other common dermatological diseases such as hand eczema or lichen planus, owing to their chronicity and hyperpigmentation. Recently, a single case with isolated palmar involvement in leprosy has been reported from the United States. ${ }^{14}$ The major limitation of this study was its retrospective nature, which might have led to underreporting of palmoplantar lesions as they can often be clinically silent.

Leprosy has been eliminated from most countries in the world; however, it is a great mimicker, and newer atypical and uncommon presentations continue to occur. A high index of suspicion is necessary to diagnose such unusual presentations of leprosy, particularly those with a higher risk of reactions and disabilities such as palmoplantar involvement, and timely and appropriate management helps to improve the patient's quality of life.

Received August 13, 2019. Accepted for publication December 15, 2020.
Published online February 16, 2021.

Acknowledgments: The American Society of Tropical Medicine and Hygiene (ASTMH) assisted with publication expenses.

Authors' addresses: Garima Dabas, Tarun Narang, and Sunil Dogra, Department of Dermatology, Venereology and Leprology, Postgraduate Institute of Medical Education and Research (PGIMER), Chandigarh, India, E-mails: drgarimadabas@gmail.com, narangtarun@ yahoo.co.in, and sundogra@hotmail.com. Divya Aggarwal and Bishan Das Radotra, Department of Histopathology, Postgraduate Institute of Medical Education and Research (PGIMER), Chandigarh, India, E-mails: divya.Ih.1@gmail.com and bishanradotra@gmail. com

\section{REFERENCES}

1. Hastings RC, Brand PW, Mansfield RE, Ebner JD, 1968. Bacterial density in the skin in lepromatous leprosy as related to temperature. Lepr Rev 39: 71-74.

2. Hopkins R, Denney OE, Johansen FA, 1929. Immunity of certain anatomic regions from lesions of skin leprosy. Arch Dermatol Syphilol 20: 767-779.

3. Agrawal US, Bhargava P, Gulati R, Mathur NK, 1997. Palmoplantar nodular lesions in lepromatous leprosy. Int $J$ Lepr Other Mycobact Dis 65: 500-502.

4. Anish SA, 1971. The relationship between surface temperature and dermal invasion in lepromatous leprosy. Int $J$ Lepr Other Mycobact Dis 39: 848-851.

5. Bedi TR, Kumar B, Kaur S, 1979. Histopathologic study of clinically normal appearing skin in lepromatous leprosy. Lepr India 51: 78-80.

6. Katoch VM, Mukherjee A, Girdhar BK, 1980. A bacteriological and histopathological study of apparently normal skin in lepromatous leprosy. Lepr India 52: 508-512.

7. Kaur S, Kumar B, 1978. Study of apparently uninvolved skin in leprosy as regards bacillary population at various sites. Lepr India 50: 38-44.

8. Indira D, Kaur I, Sharma VK, Das A, 1999. Palmoplantar lesions in leprosy. Indian J Lepr 71: 167-172. 
9. Enna CD, Berghtholdt HT, Stockwell F, 1974. A study of surface and deep temperatures along the course of the ulnar nerve in the pisohamate tunnel. Int J Lepr Other Mycobact Dis 42: 43-47.

10. Sabin TD, Hackett ER, Brand PW, 1974. Temperatures along the course of certain nerves often affected in lepromatous leprosy. Int J Lepr Other Mycobact Dis 42: 38-42.

11. Chattopadhyay SP, Gupta CM, 1988. Primary hyperpigmented cutaneous lesions in tuberculoid leprosy. Indian J Lepr 60: 63-65.
12. Arakkal G, Vani S, Kasetty HK, Varala S, 2015. Leprosy: an unusual presentation. Int J Med Public Health 5: 118-120.

13. Arora SK, Mukhija RD, Mohan L, Girdhar M, Sharma SP, 1989. A study of palmo-plantar lesions in leprosy: a preliminary report. Indian J Lepr 61: 206-208.

14. Awali $\mathrm{R}$, Chandrasekar $\mathrm{PH}, 2018$. Hyperpigmented macule on the palm and diminished sensation. JAMA 320: 20292030. 